\title{
Emotional intelligence and internet addiction among nursing interns
}

\author{
Azza Fathi Ibrahim *1, Dalal Talat Akel², Laila Abbass Mahmoud Abd El Fatah ${ }^{3}$, Mohammad Othman Abudari ${ }^{4}$ \\ ${ }^{1}$ Nursing Education Department, Faculty of Nursing, Alexandria University, Egypt \\ ${ }^{2}$ Nursing Administration Department, Faculty of Nursing, Ain Shams University, Egypt \\ ${ }^{3}$ Psychiatry Mental Health Nursing Department, Technical nursing institute - National cancer institute, Cairo University, Egypt \\ ${ }^{4}$ Community Health Nursing Department, Faculty of Nursing, Batterjee Medical College, Saudi Arabia
}

Received: August 2, 2015

DOI: $10.5430 /$ cns.v4n1p70
Accepted: December 28, $2015 \quad$ Online Published: January 14, 2016

URL: http://dx.doi.org/10.5430/cns.v4n1p70

\begin{abstract}
Nursing graduates, during the internship period, carry a lot of duties and responsibilities which obligates them to use proficient emotional abilities. Emotional intelligence (EI) is the aptitude to manage emotions intelligently which includes a group of emotional and cognitive competencies. There are multiple factors that affect EI. One of them is internet addiction (IA). The aims of this study are to determine the EI and IA levels among nursing interns and to investigate the relationship between them. Hence, the research employed a descriptive, correlative survey which was conducted on all nursing interns who enrolled at the Faculty of Nursing, Ain Shams University, Egypt. The survey instrument included the Trait EI Questionnaire Short Form (TEIQue SF) and the Problematic Internet Use Questionnaire (PIUQ). In addition, sociodemographic assessment was involved. According to the findings of this study, the majority of nursing interns have high EI scores concerning, well being, self control, emotionality and sociability. Also, a greater number of nursing interns have low scores pertaining to obsession, neglect and self control of IA components. There is a statistically significant relation between participants' socio-demographic characteristics and EI scores and IA scores. Additionally, there is an evidence of negative or inverse correlation between IA and EI among nursing interns. Conclusion and recommendations: EI and IA are negatively correlated among graduate nursing interns. These two important concepts should be investigated and integrated into the nursing curriculum. As well, nursing interns should be trained on how to develop EI skills and use of the internet in a proper way.
\end{abstract}

Key Words: Internet addiction, Emotional intelligence, Nursing interns

\section{INTRODUCTION}

In Egypt, internship nursing students are in the fifth year of their nursing faculty study which focused on field experience only. They can be certified to employment career after passing this clinical training year. In this time the students pass through extensive and comprehensive clinical training in field experience under faculty supervision and evaluation, while carrying full duties and responsibilities in their as- signed clinical practice. Interns seek guidance and advice from their preceptors without any courses or classes. They carry a job of training and working load in the same time in different health settings in Egypt according to their demographic distribution. Generally, an internship consists of an exchange of services for experience between the student and an organization. ${ }^{[1-3]}$

The nursing internship period is considered a stressful time

\footnotetext{
${ }^{*}$ Correspondence: Azza Fathi Ibrahim; Email: nursing14.jed@ bmc.edu.sa; Address: Nursing Education Department, Faculty of Nursing, Alexandria University, Egypt.
} 
of transition among graduate nursing students, due to the role adjustment and competent practice development in this period. Extensive shortages among nursing employees in health settings is a fact yet graduate nursing turnover is anticipated to be very minimal. This is because they become a major part of hospital staffing. As well, many hospitals view nursing interns as an urgent and magical solution to the lack of nursing employees rather than a long-term strategy for professional development and retention. Therefore, nursing graduates in internship suffer from massive duties, tasks and emotional loads. ${ }^{[2-4]}$ Selecting proficient emotional ability to deal with several traumatic and difficult field experiences is required for nursing interns, such as Emotional intelligence (EI) aptitudes. EI enhances nursing graduates in conveying emotionally competent nursing practices, making communication easy and facilitating decision making. As well, these skills enable them to adapt in new clinical surroundings, and be satisfied and motivated in their assigned roles. ${ }^{[4-6]}$

EI refers to the capability to motivate oneself and continue in the face of frustration; to control impulse and delay gratification; to adjust one's mood and remove distress from swamping the ability to think; and to empathize and to hope. ${ }^{[7-9]}$ Therefore, EI is an essential requirement in health care practices, particularly in the nursing field. EI supports nurses in handling their emotional responses, being empathetic and able to exchange feelings without establishing conflict and managing instinctive emotions, such as disgust, annoyance and frustration, in nurse-patient interactions. ${ }^{[5,7,8]}$ EI consists of five basic social and emotional competencies: selfawareness, self-regulation, motivation, empathy and social skills. Petrides KV, and Furnham A, in 2001, developed a global trait intelligence scale to clarify emotional competencies through representing overall factors: well-being, selfcontrol, emotionality and sociability. EI is an assemblage of emotion-related dispositions and self-perceptions situated at the lower levels of personality hierarchies. EI plays a critical part in structuring successful therapeutic nurse-patient relationships through understanding patient perspectives and establishing the deepest rapport. Such as emotional work, empathy and counseling skills can result in patients' emotional states being modified and anxiety being ameliorated. One of the most apparent factors that may affecting our EI, is Internet addiction (IA). ${ }^{[8,10,11]}$

IA is a psychological disorder proposed for inclusion in DSM-V (the American Psychiatric Association's Diagnostic and Statistical Manual of Mental Disorders, fifth revision). It is described as an impulse control disorder, which does not involve use of an intoxicating drug and is very similar to pathological gambling. Moreover, many researches define IA as a compulsive loss of impulse control resulting in damage

Published by Sciedu Press to relationships, schoolwork or employment and are followed by many social and health problems. Additionally, it is referring to excessive or poorly controlled preoccupations, urges or behaviors regarding computer use and internet access that may be determined by losing track of time, neglecting basic drives such as hunger and sleep, then it may lead to impairment or distress. Some internet users may develop an emotional attachment to on-line friends and activities they create on their computer screens for long period (exceeds 8/hours daily). Internet users may enjoy aspects of the Internet that allow them to meet, socialize, and exchange ideas through the use of chat rooms, social networking websites or "virtual communities". All these online activities affect negatively individuals' concentration, perception, thinking ability and daily living activities. ${ }^{[11,13,14]}$ Therefore IA is a health phenomena affects our health and our EI abilities, particularly in a vital job as nursing. Generally, not only with nursing interns, but with others the same age, there are several effects of IA on EI, which lead to inability to control emotions, negative or positive, throughout the addictive behavior. $^{[6,11]}$ Therefore, EI enhances the regulating of emotions that are associated with a person's mental and physical health, however, IA disturbed these regulations. ${ }^{[11-13]}$

Certainly, the internet is one type of new technology that provides widespread services as: enormous amounts of information, easier and oversimplified tasks within seconds, powerful source for shopping, minimizes distances and provides communication services efficiently and without any cost, endless navigating games, new areas of jobs in all countries and expands the availabilities of working and education tools including the greatest source of reference for educators and students. In general, the internet is a multi-tool with applications on every aspect of someone's life. Concerning health care, the internet has many advantages such as: enables patients to take informed decisions, saves life through remote consultations, facilitates earlier and effective diagnosis and guides health care interventions, faster patient history access to avoid drug overlapping or poor treatment, effective administrative coordination, video technology to increase timeliness and decrease transfer rate and cost, and provides a good facility for self management, health education, and promotion and disease prevention. Therefore, using the internet technologies is an effective tool in nursing practice for facilitating health communication among individuals, families and communities, but misusing may lead to several risks. ${ }^{[14-17]}$ Consequently, internet use is increasing every day and everywhere (at home, work, school, and university) because of its valuable paradigm for study, exploration, and leisure activities. Internet employed an unrestricted source of enjoyment, satisfaction and has great benefits for all ages. 
Internet gives a sense of stimulation and attraction to adolescents. Once they engage in the excitement of internet, they spend more and more time using it. Nevertheless, it leads to pathological use such as physical laziness, lack of exercise, depression, low self-esteem, anxiety, mood disorders and reduction of the effort to establish relationships with others. Internet use has much harm associated with over use, even though it has several benefits. ${ }^{[13-15,17]}$ Internet technologies should be tailored to people's necessities, interests and requirements. This is to avoid negative consequences such as dehumanization and depersonalization, in particular during nursing work. ${ }^{[18,19]}$ Poor employment of the internet usage is causing inflexibility in EI and psychiatric disorders that are discussed in several studies. ${ }^{[10,17,19,21]}$

Hence, nursing interns are often looking forward to understanding patient emotions. They are in a sensitive period of personality and professional development. They tend to use cognitively and meta-cognitively understanding of information to assess patient needs, and then display emotional interventions that convey caring and empathy toward patients. Accordingly, the study of EI and factors affecting it among nursing interns is a very valuable inspiration for improving nursing practice.

\subsection{Aim and significance}

This study aimed to assess the EI and IA among nursing interns and investigate the relationship between both. Nursing interns are the graduates who have mature and learnt cognitive and behavioral abilities to face the newest and condensed field experience, then handle their deepest emotions in achieving patients' goals. Furthermore, particularly with nursing interns' average age group, there are several challenges faced them, one is advancement of technology and internet usage which help and may hindering in the same time. IA is an obvious issue affecting the psychological and mental health of nursing interns that of course has a reflection on their EI abilities in nursing activities.

\subsection{Research questions}

(1) What are the EI and IA scores among nursing interns?

(2) What is the relation between EI, IA and sociodemographic characteristics of nursing interns?

(3) What is the correlation between EI and IA among nursing interns?

\subsection{Research hypothesis}

There is a significant inverse relationship between EI and IA among nursing interns.

\section{Methods}

The present study follows a descriptive correlation research design to verify the association between IA and EI among internship nursing graduates. Subjects were comprised of graduates who enrolled in the internship period: 80 male and female who agreed to participate in the study from 94 , excluding students who refused to participate or did not fill the questionnaire or included in the pilot sample. They registered in El-Demerdash University Hospital, Cairo, Egypt.

The data collection tool was a triple-section questionnaire. First part: Demographic information (age, gender, educational degree, residence, marital status, etc). Second part: Problematic Internet Use Questionnaire (PIUQ), which was developed by Demetrovics et al. in 2008 to assess the problems of IA. This part contains three subscales that represent 18 questions about IA signs: First Obsession disorders which means mental engagement with the internet-that is, daydreaming, fantasizing a lot about the internet, waiting for the next time to get online and on the other hand, anxiety, worry and depression caused by lack of internet use. This subscale includes questions $1,4,7,10,13$, and 16. The second subscale is Neglect disorders referring to neglecting everyday activities and essential needs, items about the decreasing importance of household chores, work, studies, eating, partner relations, and other activities and the neglect of these activities due to an increased amount of internet use. This subscale embodies questions $2,5,8,11,14$, and 17. The third subscale is Control disorders that denote difficulties in controlling internet use, and full dependency on it without control, which is signified by questions $3,6,9,12$, 15, and 18. The PIUQ is designed in a form of a five point Likert Scale: ranged from always $=5$ to never $=1$. The total score varies from 1-72, and is divided into 4 groups; normal $(1 \leq 17)$, low $(18 \leq 36)$, moderate $(37 \leq 54)$, and severe $(55 \leq 72)$ dependency. Third part: Trait EI Questionnaire Short Form (TEIQue SF) that was developed by Petrides and Furnham in 2001. This part is used to identify the level of EI among undergraduate students. This tool consisted of 30 content questions in a seven-point Likert-type Scale that measures trait EI. Its scores calculated for four factors: Wellbeing, Self-control, Emotionality, and Sociability. The Well-being factor indicates to which extent the individual is fulfilled and satisfied with life with high self esteem. This factor comprises questions 5, 20, 9, 24, 12, and 27. The second factor is Self-control which refers to one's degree of control over urges and desires and measures through questions 4, 19, 7, 22, 15, and 30. Emotionality is the third factor that refers to which extent the person possesses a wide array of emotion-related skills: recognizing internal emotions, perceiving emotions, and expressing emotions in between personnel relationships with family and friends. This factor encompassed questions 1, 16, 2, 17, 8, 23, 13, and 28. The final factor is Sociability that evaluates one's influence in a 
variety of social contexts, rather than just in personal relationships with family and friends. This part involves questions 6, 21, 10, 25, 11, and 26. Questions 2, 4, 5, 7, 8, 10, 12, 13, $14,16,18,22,25,26$, and 28 are reverse-coded. Questions $3,14,18$, and 29 contribute only to the global trait EI score. This scale was modified to be a five-point Likert Scale with response categories namely strongly agree $=5$, agree $=4$, neutral $=3$, disagree $=2$ and strongly disagree $=1$. Total score ranged from 30 to 150 , in terms of: $30 \leq 70$ indicates low EI; $71 \leq 110$ represents moderate EI and $111 \leq 150$ points to high EI.

This part measures the IA as a psychological disorder, so, the score ranges from always to never which indicates to which extend using of internet affects human life activities. EI is a personality trait or ability so it can be high, moderate or low. Consequently the scale was developed to measure this traight by this manner. Study tool was revised, adopted and modified by the researchers after a thorough review of related literature. Tool was submitted to a jury of seven experts in nursing education, administration and psychiatric nursing fields to determine its applicability and content validity after which the necessary modifications were done. The study tool was statistically tested for reliability using test and retest reliability. For PIUQ questionnaire, $(r=.84)$ splitting $(r=.82)$ and Cronbach's alpha $(r=.81)$. For TEIQue SF questionnaire, $(r=.83)$ splitting $(r=.80)$ and Cronbach's alpha $(r=.77)$. Internal validity has been assessed to be higher than $82 \%$ and it is reported as significant in test-retest method for both PIUQ and TEIQue SF questionnaires.

\subsection{Ethical considerations}

Written approvals were taken from the Faculty of Nursing and Ain Shams University, Cairo, Egypt, after ethical committee approval document obtained. Written informed consent was obtained before attaining the participants' voluntary involvement in tool completion. Nursing interns have to sign an informed consent which included the purpose of the study and their rights to participate or withdraw at any time without any negative consequences in their internship grading. Upon written agreement, the nursing graduates were given the questionnaire in the presence of the researcher to clarify any vague questions. Anonymity was assured by telling the interns to avoid putting their names on the questionnaire.

\subsection{Procedure}

A pilot study was carried out on nine nursing interns who were selected randomly apart from the study sample to test tool clarity, feasibility, time needed to fill and understanding of the study tool. Questionnaire copies were distributed among the interns' students in their shifts of morning and evening and the estimated time needed for filling question- naire was 20 to 30 minutes.

\subsection{Statistical analysis}

Data was fed, coded, edited and analyzed using the PC with Statistical Packages for Social Science (SPSS 22) and Windows Version 7.0. The selected level of significance was $p$-level <.05. Descriptive statistics were done using numbers, percentage, arithmetic mean and standard deviation. Then Univariate analyses were performed by use of the Chi-square test and variance analysis in $95 \%$ confidence levels, besides Spearman's rho statistical test which was used to quantify the strength of the association between the study variables.

\section{RESUlts}

Subjects were comprised of graduates' interns who enrolled in the internship period: 80 male and female who agreed to participate in the study. Table 1 shows that more than two thirds of nursing interns (70\%) were in their early twenties and about all $(81.15 \%)$ of them were female, plus over half $(58.75 \%)$ were single. About the same percent $(65 \%)$ of the study subjects were from urban areas and the identical percentage $(65 \%)$ has only high school certificates before joining the nursing faculty. Also, a significant part of the study subjects (70\%) used the internet daily while slightly less than this part (62.5\%) faced work problems daily.

Table 1. Percent distribution of nursing interns according to their socio-demographic characteristics

\begin{tabular}{lll}
\hline Socio-demographic characteristics $(\mathbf{n}=\mathbf{8 0})$ & No. & $\mathbf{\%}$ \\
\hline Age & 56 & 70 \\
$\quad 20-23$ & 10 & 12.5 \\
$24-27$ & 14 & 17.5 \\
$28-30$ & 0 & 0.00 \\
$\quad$ Older than 30 & & \\
Gender & 65 & 81.15 \\
$\quad$ Female & 15 & 18.75 \\
$\quad$ Male & & \\
Marital status & 47 & 58.75 \\
$\quad$ Single & 22 & 27.5 \\
$\quad$ Married & 8 & 10 \\
$\quad$ Divorced & 3 & 3.75 \\
$\quad$ Other (widow) & & \\
Residence & 52 & 65 \\
$\quad$ Urban & 28 & 53 \\
$\quad$ Rural & & \\
Qualification before joining nursing college & 52 & 65 \\
$\quad$ High school & 18 & 22.5 \\
$\quad$ Technical diploma & 10 & 12.5 \\
$\quad$ Bachelor from other faculty & & \\
Use of internet/week & 56 & 70 \\
$\quad$ Daily & 22 & 27.5 \\
$\quad$ Every two days & 2 & 2.5 \\
$\quad$ Every three days & 0.00 \\
$\quad$ Once weekly & 50 & \\
Exposure to work problems & 12 & 15 \\
$\quad$ Daily & 8 & 10 \\
$\quad$ Every two days & 10 & 12.5 \\
$\quad$ Every three days & & \\
Once weekly & & \\
\hline & & \\
\hline
\end{tabular}


Table 2. Percent distribution of nursing interns according to their EI scores

\begin{tabular}{|c|c|c|}
\hline Emotional Intelligence scores $(\mathrm{n}=\mathbf{8 0})$ & No. & $\%$ \\
\hline \multicolumn{3}{|l|}{ Wellbeing } \\
\hline Low & 14 & 17.5 \\
\hline Moderate & 8 & 10 \\
\hline High & 58 & 72.5 \\
\hline \multicolumn{3}{|l|}{ Self-control } \\
\hline Low & 12 & 15 \\
\hline Moderate & 12 & 15 \\
\hline High & 56 & 70 \\
\hline \multicolumn{3}{|l|}{ Emotionality } \\
\hline Low & 22 & 27.5 \\
\hline Moderate & 14 & 17.5 \\
\hline High & 44 & 55 \\
\hline \multicolumn{3}{|l|}{ Sociability } \\
\hline Low & 32 & 40 \\
\hline Moderate & 12 & 15 \\
\hline High & 36 & 45 \\
\hline \multicolumn{3}{|l|}{ Total scores for Emotional Intelligence } \\
\hline Low & 20 & 25 \\
\hline Moderate & 12 & 15 \\
\hline High & 48 & 65 \\
\hline
\end{tabular}

In relation to the scores of EI, Table 2 clarifies that about three quarters of nursing interns $(72.5 \%, 70 \%)$ have high EI scores concerning well being and self control while about half of them $(55 \%, 45 \%)$ have high EI scores regarding emotionality and sociability. The majority of study subjects have high scores in EI in general.

Concerning the findings in Table 3, pertaining to the relationship between subjects' socio-demographic characteristics and EI scores, the majorities of nursing interns who have high EI were singles $(42.5 \%)$, females $(55 \%)$, come from urban areas (35\%), use the internet daily (39\%) and are exposed to work problems daily $(42.5 \%)$. This is compared with the smallest percents with low or moderate EI scores who were males, married, came from rural areas, used the internet every two or three days and were exposed to work problems every two or three days. The difference was statistically significant between all subjects characteristics and EI scores except in residence $\left(\chi^{2}=2.12\right.$ and $\left.p=.346\right)$.

Consistent with the data in the Table 4 concerning Problematic Internet Use scores, all study subjects have IA problem scores (there are no subjects who having normal scores) which is explained: there is no one $(0.00 \%)$ of nursing interns were free from problems in using internet, but the majority of them $(82.5 \%, 75 \%, 85 \%)$ have low scores in: obsessions, neglect, and control disorders. Therefore, a greater part of the subjects have low scores in IA and only $7.5 \%$ of them have severe IA problems.

Table 3. Distribution of nursing interns according to EI scores and their socio-demographic characteristics $(\mathrm{n}=80)$

\begin{tabular}{|c|c|c|c|c|c|c|c|c|}
\hline \multirow{2}{*}{ Socio-demographic characteristics } & \multicolumn{2}{|l|}{ Low } & \multicolumn{2}{|c|}{ Moderate } & \multicolumn{2}{|c|}{ High } & \multicolumn{2}{|c|}{ Statistical test } \\
\hline & No. & $\%$ & No. & $\%$ & No. & $\%$ & $\chi^{2}$ & $p$ \\
\hline \multicolumn{9}{|l|}{ Gender } \\
\hline Male & 7 & 8.75 & 4 & 5 & 4 & 5 & 15.38 & $.00045^{*}$ \\
\hline Female & 13 & 16.25 & 8 & 10 & 44 & 55 & & \\
\hline \multicolumn{9}{|l|}{ Marital status } \\
\hline Single & 5 & 6.25 & 8 & 10 & 34 & 42.5 & & \\
\hline Married & 10 & 12.5 & 2 & 2.5 & 10 & 12.5 & 14.89 & $.02113^{*}$ \\
\hline Divorced & 4 & 5 & 2 & 2.5 & 2 & 2.5 & & \\
\hline Others (widow) & 1 & 1.25 & 0 & 0.00 & 2 & 2.5 & & \\
\hline \multicolumn{9}{|l|}{ Residence } \\
\hline Urban & 12 & 15 & 10 & 12.5 & 30 & 35 & 2.12 & .346 \\
\hline Rural & 8 & 10 & 2 & 2.5 & 18 & 22.5 & & \\
\hline \multicolumn{9}{|l|}{ Use of internet/week } \\
\hline Daily & 12 & 15 & 5 & 6.25 & 31 & 38.75 & & \\
\hline Every two days & 8 & 10 & 5 & 6.25 & 9 & 11.25 & 13.88 & $.00769^{*}$ \\
\hline Every three days & 0 & 0.00 & 2 & 2.5 & 0 & 0.00 & & \\
\hline Once weekly ${ }^{\#}$ & 0 & 0.00 & 0 & 3.75 & 0 & 0.00 & & \\
\hline \multicolumn{9}{|l|}{ Exposure to work problems } \\
\hline Daily & 41 & 17.5 & 2 & 2.5 & 34 & 42.5 & & \\
\hline Every two days & 3 & 3.75 & 5 & 6.25 & 4 & 5 & 17.73 & $.00694^{*}$ \\
\hline Every three days & 3 & 3.75 & 2 & 2.5 & 3 & 3.75 & & \\
\hline Once weekly & 0 & 0.00 & 3 & 3.75 & 7 & 8.75 & & \\
\hline
\end{tabular}

"Significant at $p<.05 ;{ }^{*}=$ removed from calculation 
Table 4. Percent distribution of nursing interns according to their Problematic Internet Use scores

\begin{tabular}{lll}
\hline \multirow{2}{*}{ Problematic Internet Use scores } & \multicolumn{2}{l}{ Nursing interns (n= 80) } \\
\cline { 2 - 3 } & No. & \% \\
\hline Obsession disorders & 0 & 0.00 \\
Normal & 66 & 82.5 \\
Low & 4 & 5 \\
Moderate & 10 & 12.5 \\
Severe & & \\
Neglect disorders & 0 & 0.00 \\
Normal & 70 & 87.5 \\
Low & 0 & 0.00 \\
Moderate & 10 & 12.5 \\
Severe & & \\
Control disorders & 0 & 0.00 \\
Normal & 68 & 85 \\
Low & 21 & 15 \\
Moderate & 0 & 0.00 \\
Severe & & \\
Total score for internet addiction & & 0.00 \\
Normal & 0 & 85 \\
Low & 68 & 7.5 \\
Moderate & 6 & 7.5 \\
Severe & 6 & \\
\hline
\end{tabular}

Table 5 clarifies the relation between participants' characteristics and IA scores. About three quarters of female sub- jects $(73.75 \%)$ have low IA scores compared with $11.25 \%$ of males. Very minimal percents among male or female nursing interns have severe IA scores. More than one half among single subjects $(53.7 \%)$ have low IA, against one quarter approximately $(23 \%, 7 \%)$ among married interns. There are negligible percents with single, married, divorced or widowed interns who have moderate or severe IA scores.

More than one half $(52.5 \%)$ of nursing interns have low IA scores who came from urban areas while $(32.5 \%)$ came from rural areas and have the same low IA score. About two thirds of the subjects (62.5\%) used the internet daily and having low IA score, dissimilarity with smallest percents among those who are using the internet every two or three days or weekly and got the same lower scores. In relation to exposure to work problems, more than one half (55\%) of nursing interns have low IA scores, were exposed to work problems daily compared with few percents for those exposed to these problems every two or three days and got the same lower scores.

Generally, very smallest percents of study subjects have moderate or severe IA scores with all different socio-demographic characteristics; the majority of them have low IA scores. There were statistically significant differences between nursing interns' socio-demographic variables and IA scores except in relation to residence and gender.

Table 5. Distribution of nursing interns according to IA scores and their socio-demographic characteristics $(\mathrm{n}=80)$

\begin{tabular}{|c|c|c|c|c|c|c|c|c|}
\hline \multirow{2}{*}{ Socio-demographic characteristics } & \multicolumn{2}{|c|}{ Low $(n=68)$} & \multicolumn{2}{|c|}{ Moderate $(n=6)$} & \multicolumn{2}{|c|}{ Severe $(n=6)$} & \multicolumn{2}{|c|}{ Statistical test } \\
\hline & No. & $\%$ & No. & $\%$ & No. & $\%$ & $\chi^{2}$ & $p$ \\
\hline \multicolumn{9}{|l|}{ Gender } \\
\hline Male & 9 & 11.25 & 2 & 2.5 & 4 & 5 & 3.86 & $.0145^{*}$ \\
\hline Female & 59 & 73.75 & 4 & 5 & 2 & 2.5 & & \\
\hline \multicolumn{9}{|l|}{ Marital status } \\
\hline Single & 43 & 53.7 & 2 & 2.5 & 2 & 2.5 & & \\
\hline Married & 19 & 23.7 & 2 & 2.5 & 1 & 1.2 & 42.85 & $.00001^{*}$ \\
\hline Divorced & 6 & 7.5 & 2 & 2.5 & 0 & 0.0 & & \\
\hline Widow & 0 & 0.00 & 0 & 0.00 & 3 & 3.75 & & \\
\hline \multicolumn{9}{|l|}{ Residence } \\
\hline Urban & 42 & 52.5 & 4 & 5 & 6 & 7.5 & 3.55 & .169 \\
\hline Rural & 26 & 32.5 & 2 & 2.5 & 0 & 0.00 & & \\
\hline \multicolumn{9}{|l|}{ Use of internet/week } \\
\hline Daily & 50 & 62.5 & 4 & 5 & 2 & 2.5 & & \\
\hline Every two days & 17 & 21.2 & 1 & 1.2 & 4 & 5 & 10.30 & $.036^{*}$ \\
\hline Every three days & 1 & 1.25 & 1 & 1.2 & 0 & 0.0 & & \\
\hline Once weekly ${ }^{\#}$ & 0 & 0.00 & 0 & 0.00 & 0 & 0.00 & & \\
\hline \multicolumn{9}{|l|}{ Exposure to work problems } \\
\hline Daily & 44 & 55 & 5 & 6.2 & 1 & 1.2 & & \\
\hline Every two days & 11 & 13.7 & 1 & 1.2 & 0 & 0.0 & 40.22 & $.00001^{*}$ \\
\hline Every three days & 3 & 3.75 & 0 & 0.0 & 5 & 6.2 & & \\
\hline Once weekly & 10 & 12.5 & 0 & 0.00 & 0 & 0.00 & & \\
\hline
\end{tabular}

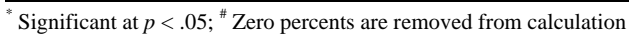


Table 6. Correlation between IA and EI scores among nursing interns as presented by number and percentage

\begin{tabular}{|c|c|c|c|c|c|c|c|c|c|}
\hline \multirow{3}{*}{ Correlation } & & \multicolumn{6}{|c|}{ Internet Addiction } & \multirow{2}{*}{\multicolumn{2}{|c|}{ Statistical test }} \\
\hline & & \multicolumn{2}{|c|}{ Low $(n=68)$} & \multicolumn{2}{|c|}{ Moderate $(n=6)$} & \multicolumn{2}{|c|}{ Severe $(n=6)$} & & \\
\hline & & No. & $\%$ & No. & $\%$ & No. & $\%$ & $r$ & $p$ \\
\hline \multirow{3}{*}{ Emotional Intelligence } & Low $(\mathrm{n}=20)$ & 14 & 17.5 & 2 & 2.5 & 4 & 5 & $-.316^{* *}$ & .004 \\
\hline & Moderate $(\mathrm{n}=12)$ & 9 & 11.25 & 1 & 1.25 & 2 & 2.5 & & \\
\hline & High $(n=48)$ & 45 & 56.2 & 3 & 3.75 & 00 & 0.00 & & \\
\hline
\end{tabular}

Correlation Coefficient is significant at the .01 level (2-tailed); Spearman's rho used to quantify the strength of association between 2 numerical ordinal variables

Table 7. Multi regressions analyze results to estimate IA, of nursing interns according to EI

\begin{tabular}{lllll}
\hline Meaning level & T-test & Standard coefficient & Unstandard coefficient & Predictive \\
\hline $0 / 000$ & $8 / 39$ & & $64 / 095$ & Constant number \\
$0 / 000$ & $-4 / 49$ & $-0 / 303$ & $-0 / 284$ & Emotional Intelligence \\
\hline
\end{tabular}

Table 6 shows the correlation and association between IA and EI scores among nursing interns. There is a clear inverse proportion between both variables where Spearman's rho association test $r=-.316$. The highest percent of nursing interns $(56.25 \%)$, who have low IA scores, is approximately, the same highest percent of nursing interns who have high EI scores. This supports the research hypothesis.

According to the obtained data, from Table 6, the predictive variables in the study, have determined the variance of IA users to be low (56.2\%), while the same percent is obtained by interns who have high EI. On the other hand, there is no interns complain with severe IA, and consequently no percent for high EI, respectively. The correlation coefficient among IA and emotional EI is significant relation.

According to the findings in Table $7, R^{2}=0.087$ which means only $9 \%$ of IA difference verify with EI variable. The amount of $\mathrm{R}(0.303)$ and $\mathrm{F}$ index show that linear regression model is good to estimate. Coefficient of EI is positive (0.303). The considerable level of $T$-test score illustrates that there is a significant correlation between these variables and forecasting for IA according EI, can be examined. According to the correlation between these two variables, it is effortless to judge about 0.303 unit decline of EI after 1 unit increase of IA.

\section{Discussion}

Nursing graduates in the internship period, pass through a critical experience of transitioning from an educational program to a work setting. This time has been generally accompanied with stress, role change, and reality shock. Although there are a lot of challenges confronting nursing interns, there are few research evidences. ${ }^{[1,2]}$ Internet use and EI are apparent issues that should be addressed and investigated among this group. According to the results from the current study, demographic profiles were analyzed with the majority of nursing interns being female and in their early twenties. The male gender in the field of nursing is still low in numbers. In the same line which was discussed by Abd El-Halem et al. in 2011, that there are several opportunities for male students to take positions in hospitals and community health settings, but there are still an insignificant number in nursing work. ${ }^{[2,22]}$ A significant part of the participants came from urban areas due to the geographical location of the college, whereas the rural and remote areas provided mostly minimum numbers of students joining a nursing career. Students from rural backgrounds achieved similar levels of success in nursing education, but with lower acceptance rates when compared with urban students. Urban areas usually have widespread use of the internet and technology where the nature of life is more sophisticated and varied. ${ }^{[3,23]}$ Moreover, a greater part of the study subjects have only a high school certificate before joining the nursing college, use the internet daily and are exposed to many work problems. Matching with this result, Coombes et al. in 2008 clarified that the intern year is a time for strengthening academic education with applying clinical practice and skills acquisition as well as gaining competency in facing work challenges. ${ }^{[24]}$

To answer the first research question, and pertaining to EI scores, the majority of nursing interns have high EI scores concerning all EI components; well being, self control and emotionality except in sociability where $45 \%$ of the subjects have high scores which is about one half of study subjects. Intern students are prepared with knowledge, skills and values that equip them to go through the internship experience in extremely stressful work environments. Therefore, it is not a surprising result that the study subjects obtain high EI skills abilities. This finding is similar with Casey et al. in 2004, who stressed that the transition of the interns from 
students to practicing professional nurses and the move from a familiar educational environment with basic foundations of nursing sciences to the workforce where expectations are to rapidly function as a competent nurse. ${ }^{[1,18,25]}$ On the other hand, Coombes in 2008 conducted a study about intern errors, where mentioned that the most noticeable clinical errors are found in the first year after nursing graduation. This is, of course, as a result of their shock with reality, lack of learning transfer skills and work stress. ${ }^{[24]}$ Nursing interns similar to other healthcare discipline does have evidence of some clinical errors documented in their interns practice. ${ }^{[24,25]}$

A greater portion of study subjects have high EI scores in the well-being factor, which indicates to which extent they are fulfilled and satisfied with life and have high self esteems. This signifies that interns can manage and are satisfied with personally important events and have a reflective influence on thought perception and behavior. ${ }^{[6,26]}$ Similarly, concerning self control, the nursing interns proved that they can control their urges and desires through their emotions and maintain a balance needed for a more healthy life. ${ }^{[4,20,26]}$ As well, they have high scores in emotionality, which denotes their wide range of emotion-related skills; recognizing internal emotions, perceiving emotions, and expressing emotions between personal relationships with colleagues. ${ }^{[7,20]}$ This is congruent with Goleman in 1995 and in 1998, who illustrated that EI maintains the integration of an individual's cognitive abilities and personality reflected in workplace performance and peer relationship. ${ }^{[27,28]}$ This is opposite to the point of view that the experience of the graduate nursing intern constantly requires role socialization support and frequent clinical orientation to overcome poor self control and relationship and social role disturbance. ${ }^{[29,30]}$

In the fourth EI component, less than one half of nursing interns have high scores, which is not an insignificant percent, that represent sociability in which the nurse tends to evaluate one's own influence in a variety of social contexts, rather than just in personal relationships with family and friends. This component is the higher and deepest element of EI and clarifies the recognizing of one's own feelings and those of others, motivating one and others, and managing emotions well with self awareness and other interaction. In matching with this view, self-awareness should involve knowing when feelings are present in the self and others, and being able to label feelings with words expressing the specific feeling. It is the highest level of EI, and means being able to predict feelings in advance. ${ }^{[6,20,31]}$ Our nursing interns have a valuable percent in this deepest EI competency, even if this percents were fewest against other EI competences percents.

Concerning the relationship between subjects' socio- demographic characteristics and EI scores, the majorities of nursing interns who have high EI were singles, females, come from urban areas, use the internet daily and are exposed to work problems daily. These results are harmonious with Hamissi et al. in 2013 who explained that EI varies from person to person, while there is a strong positive relation with life style, gender, life satisfaction, social relation and qualification. Dissimilarly, sex differentiation didn't play a role on problem solving ability. Plenty of studies found that there is no significant relation between EI, sex, and social status. ${ }^{[9,32]}$

In relation to IA scores descriptions, all study subjects have IA problems because they haven't got scores of normal internet usage. The majority of study subjects have low scores of internet problems: obsessions, neglect, and control disorders. Nursing interns have remarkable low scores which can be inconsiderable problem. In agreement with this point of view, the number of internet users is shockingly rising. It has been described that this figure are more than 11.5 million people around the world, particularly among youth, but problems with it are rarely noticed. Consequently, threats can be occurs and felt among who do not follow acceptable standards in using the internet. ${ }^{[19,21,33]}$

Problems with obsession refers to mental engagement with the internet and visualizing a lot about the internet in dreams and then waiting for the next time to get online, followed by anxiety, worry, and depression caused by lack of Internet use. Congruently, there are numerous studies examining the side effects of current technology and internet use on mental or physical health and the accompanying dangerous signs of stress and psychiatric disorders. There is a significant relation between internet use and psychiatric signs like aloneness, depression and obsession. ${ }^{[34,35]}$

For neglect disorders, high percents of the nursing interns have low scores in this problem, which means that interns with internet use have minimal level of neglecting everyday activities and essential needs in the home, work, studies, partner relations and other daily living activities. This fits with that intensive internet use leading to neglect of other life areas, declining educational and work achievement, decreasing sleeping time, reduced quality of meals, and a narrowing range of interests, but minimal using of internet may have a very little of these disturbances. ${ }^{[36,37]}$

The last element of IA problems is control disorders that denote difficulties in controlling internet use and full dependency on it. Our nursing interns have high percentages in this aspect but with low scores. As a result, they can overcome it effortlessly. Using the terms excessive or problematic in- 
ternet use goes together with its control and the dependency level besides the recognition of its addictive nature. The person who uses the internet more often and/or for a longer without previously planned, accordingly, was not able to decrease the amount of internet use. Control disorders are very bad signs of internet problems that affect negatively in work especially if this work is in the health care field. ${ }^{[2,10,13]}$ Compatible with this insight, control disorders in IA are an unbeatable aspiration to engage in a given conduct. ${ }^{[35]}$

Accordingly, the problems of IA in particular with control disorder must be well handled for effective intern work roles.

In accordance with the current results, with reference to the relation between participants' characteristics and IA scores, approximately two thirds of females' subjects have low IA scores compared with a minimal proportion among males. This finding is unexpected because there is a general impression that males use the internet more than females, but the present study proved the opposite of this prediction. Therefore, and contradictory to this result, young males are generally believed to constitute the majority of internet users. Moreover, mobile and internet use by females was perceived to be less than males because of their tendency for more real family and social relations more than virtual internet social ones. ${ }^{[21,38]}$ It can be justified that males use mobile and internet more than females due to several reasons such as financial activities and earning purposes.

Furthermore, there is a statistically significant difference between IA scores and the socio-demographic variables of the nursing interns. This comes in line with $\mathrm{Li}$ et al. 2010, who reported that due to the noteworthy biological, psychological, and social changes during the youth period, individuals have to face many challenges from family, school, and peer settings. Many stresses, loads and physical changes might affect the way in using the internet and lead to its dependency and problematic use. ${ }^{[38,39]}$ Our intern students pass through a difficult age point including many personality challenges which may lead to dangerous consequences such as internet use problems.

One of the most essential finding in the recent study, there is a statistically significant correlation between IA and EI among nursing interns, which clarified by multi regressions analysis results. There is an understandable inverse relation between both. The highest percent of study subjects who have low IA scores is nearly the same highest percent of them with high EI scores. This result answers the third research question and supports the research hypothesis. This finding is fitting with Far in 2014, who found that EI is significantly, negatively correlated to IA. In addition, experts clarify that people with deprived affect may not be able to regulate distressing emotions and have a limited ability to communicate these feelings with others. Therefore, frequent internet users tend to be lonely, have unexpected values, and lack in social features of EI. Addictive persons to internet use may have several risky consequences such as failing in school, and family and relationship problems. As well, they tend to have a diversity of negative growth effects; for example depression, social isolation and especially time-disruption that is equivalent with low EI. ${ }^{[11,15,19]}$ Hence, people with a high IA habit mostly have low EI skills and vice viscera.

Moreover and consistent with the current results, all the elements of EI are significantly negatively correlated with IA in terms of wellbeing, self control, emotionality and sociality. Impulsive, aggressive and dependent behaviors with IA tend to be decreased against all EI skills. Youth can be described as shyness $v s$. hostile, out of control vs. highly controllable and external problems vs. internal problems. Thus, this will lead to social isolation, anxiety, depression and somatic complaints. ${ }^{[11,21,40]}$

On the other hand, those with higher EI can control their internet dependency or excessive internet use. High EI is a bridge to better interpersonal relationships and a conquering of life pressures. Accordingly, learning EI skills are excellent insights which immediately will be reflected in a healthy and stable life and in particular enhance using the internet moderately. Unnecessary internet use evidently produces a health risk for a considerable segment of our nursing youth.

Therefore, effective preparation for professional graduate nurses, and particularly nursing interns, should be designed to strengthen their ability to recognize their own and other perceptions and how to be empathic to their concerns, gain emotionally intelligent abilities and then use the internet appropriately according to necessity. ${ }^{[41,42]}$ Nursing interns are required to manage plentiful clinical situations, adapt to different personality styles and patient expectations, work independently toward objectives, and handle conflicts. These situations require delivering emotional competence without any negative factors or surrounding barriers.

\section{CONCLUSION AND RECOMMENDATIONS}

Based on the results of this study, nursing interns at the Faculty of Nursing, Ain Shames University, had high EI with low IA levels and that there is a negative correlation between both. Thus, it was recommended that nursing interns should attend several trainings on how to use the internet effectively without any addictive features. Also, EI should be checked prior to entrance into the Faculty of Nursing. EI and IA are two important concepts that should be integrated into the nursing curriculum. Regular educational workshops and 
seminars should be also conducted for the nursing interns and their mentorship to provide enough training on how to develop EI skills and use the internet in a proper way. Further research is required to study the effect of implementing intervention programs to develop and improve EI skills of nursing interns. Additional research is needed also to determine the factors that contribute to IA among nursing interns. Furthermore, experimentation with a more comprehensive level of analysis is necessary to examine causes and effects of pathological internet use and EI.

\section{REFERENCES}

[1] Casey K, Fink R, Krugman M, et al. The Graduate Nurse Experience. Journal of Nursing Administration. 2004; 34(6): 3033011. PMID:15190226. http://dx.doi.org/10.1097/0000511 0-200406000-00010

[2] Oermann MH, Garvin MF. Stresses and Challenges for New Graduates in Hospitals. Nurse Education Today. 2002; 22: 225-230. PMID:12027604. http://dx.doi.org/10.1054/nedt. 2001.0 695

[3] Abdel Kader AM, Mohamed EA Abood. Perception of Nurse Interns about Clinical Assignment Preparation Requirements. Journal of American Science. 2012; 8(12): 676-682.

[4] McQueen CH. Emotional Intelligence in Nursing Work. Journal of Advanced Nursing. 2004; 47(1): 101-108. PMID:15186473. http://dx.doi.org/10.1111/j.1365-2648.2004.03069.x

[5] Duygulu S, Hicdurmaz D, Akyar I. Nursing Students' Leadership and Emotional Intelligence in Turkey. Journal of Nursing Education. 2011; 50(5): 281-285. PMID:21323258. http://dx.doi .org/10. 3928/01484834-20110130-07

[6] Smith KB, Profetto-McGrath J, Cummings GG. Emotional Intelligence and Nursing: an Integrative Literature. International Journal of Nursing Studies. 2009; 46(12): 1624-1636. PMID:19596323. http://dx.doi.org/10.1016/j.ijnurstu. 2009.05.024

[7] Mahmoud HM, Abd El-Dayem SM, Mousa M. Emotional Intelligence among Baccalaureate Students at the Faculty of Nursing, Alexandria University, Egypt: A Cross-sectional. Journal of Education and Practice. 2013; 4(27): 49-62.

[8] Corina N. The Emotional Intelligence of College and University Presidents: An Exploratory Study International Journal of Humanities and Social Science. 2011; 1(11): 1-7.

[9] Nasir M. An Exploration of Emotional Intelligence of the Students of IIUI in Relation to Gender, Age and Academic. Achievement Bulletin of Education and Research. 2010; 32(1): 37-51.

[10] Petrides KV, Furnham A. Trait Emotional Intelligence: Psychometric Investigation with Reference to Established trait Taxonomies. European Journal of Personality. 2001; 15: 425-448. http://dx. doi.o $\mathrm{rg} / 10.1002 /$ per.416

[11] Far NS, Samarein ZA, Yekleh M, et al. Relationship between the Components of Emotional Intelligence and Internet Addiction of Students in Kharazmi University. International Journal of Psychology and Behavioral Research. 2014; 3(1): 60-66.

[12] Lee J, Ok C. Reducing Burnout and Enhancing Job Satisfaction: Critical Role of Hotel Employees' Emotional Intelligence and Emotional Labor. International Journal of Hospitality Management. 2012; 31: 1101-1112. http://dx.doi.org/10.1016/j.ijhm.2012.0 1.007

[13] Demetrovics Z, Szeredi B, Rózsa S. The Three-Factor Model of Internet Addiction: The Development of the Problematic Internet Use Questionnaire. Psychonomic Society. 2008; 40(2): 563-574. http://dx.doi.org/10.3758/brm.40.2.563

[14] Malviya A, Dixit S, Shukla H, et al. A Study to Evaluate Internet Addiction Disorder among Students of a Medical College and As- sociated Hospital of Central India. National Journal of Community Medicine. 2014; 5.

[15] Parker JDA, Taylor RN, Eastabrook JM, et al. Problem Gambling in Adolescence: Relationships with Internet Misuse, Gaming Abuse and Emotional Intelligence. Pers Indiv Differ. 2008; 45: 174-180. http://dx.doi.org/10.1016/j.paid.2008.03.018

[16] E-Health and Nursing Practice; Using Technology to Complement Nursing Practice: an RCN Guide for Health Care Practitioners. UK, Royal University; 2012.

[17] Good Governance Institute. Better Care for People with Long-term Conditions. London: GGI; 2011.

[18] Barnard A, Sandelowski M. Nursing Theory and Concept Development or Analysis: Technology and Humane Nursing Care: (IR) Reconcilable or Invented Difference? Blackwell Science Ltd. 2001; 34(3): 367-375.

[19] Mesgarani M, Shafiee S, Ahmadi E, et al. Studying the Relationship between Internet Addiction and Emotional Intelligence, Sensation Seeking and Met a-cognition among those Who Referred to Cafes. International Research Journal of Applied and Basic Sciences. 2013; 4(4): 889-893.

[20] Ibrahim B. Internet Addiction and Psychological Morbidity among Nursing Students in Gaza-Palestine. American Journal of Applied Psychology. 2014; 3(4): 99-103. http://dx.doi.org/10.1164 8/j.ajap.20140304.13

[21] Hamissi J, Babaie M, Hosseini M, et al. The Relationship between Emotional Intelligence and Technology Addiction among University Students. International Journal of Collaborative Research on Internal Medicine \& Public Health. 2013; 5(5).

[22] Abdel El-Halem GE, El Hawashy ZI, Gamal El-Dein AA, et al. Undergraduate Male Nursing students' Perception about the Image of the Nursing Profession. Journal of American Science. 2011; 7(3): 614-23.

[23] Bigbee J, Mixon D. Recruitment and Retention of Rural Nursing Students: A Retrospective Study. International electronic Journal of Rural and Remote Health Research, Education, Practice and Policy. 2013; 1-10

[24] Coombes I, Stowasser D, Coombes J, et al. Why Do Interns Make Prescribing Errors? A Qualitative Study. MJA. 2008; 188(2): 89-49. PMID: 18205581.

[25] Wu A, Folkman S, McPhee S, et al. Do House Officers Learn from Their Mistakes? JAMA. 1991; 265: 2089-2094. PMID:2013929. http://dx.doi.org/10.1001/jama.1991.03460160067031

[26] Gilbert DT, Fiske ST, Lindsay G. The Handbook of Social Psychology. New York: McGraw Hill.

[27] Goleman D. Emotional Intelligence: Why It Can Matter More than IQ. New York: Bantam Books; 1995.

[28] Goleman D. Working with Emotional Intelligence. London: Bloomsbury Publishing; 1998.

[29] Owens DL, Turjanica MA, Scanion MW, et al. New Graduate RN Internship Program: a Collaborative Approach for SystemWide Integration. J Nurs Staff Dev. 2001; 17(3): 144-150. http: //dx.doi.org/10.1097/00124645-200105000-00010 
[30] Tradewell G. Rites of Passage: Adaptation of Nursing Graduates to a Hospital Setting. J Nurs Staff Dev. 1996; 12(4): 183-189. PMID:8936162.

[31] Hein S. EQ for everybody: A Practical Guide to the Developing and using one's Emotional Intelligence. 3rd ed. 2012.

[32] Shah M, Thingujam NS. Perceived Emotional Intelligence and Ways of Coping among Student. Journal of the Indian Academy of Applied Psychology. 2008; 34(1): 91-83.

[33] Ko CH, Yen JY, Yen CF, et al. The Association between Internet Addiction and Problematic Alcohol Use in Adolescents: the Problem Behavior Model. Cyber Psychology \& Behavior. 2008; 11: 571-576. PMID:18785835. http://dx.doi.org/10.1089/cpb. 2007.01 99

[34] Whang L, Lee S, Chang G. Internet Over-users' Psychological Profiles: A Behavior Sampling Analysis on Internet Addiction. Cyber Psychology \& Behavior. 2003; 6(2): 143-150. PMID:12804026. http://dx.doi.org/10.1089/109493103321640338

[35] Black DW, Belsare G, Schlosser S. Clinical Features, Psychiatric Morbidity, and Health Related Quality of Life in Persons Reporting Compulsive Computer Use Behavior. Journal of Clinical Psychiatry. 1999; 60: 839-844. PMID:10665630. http://dx.doi.org/10.40 $88 / J C P . v 60 n 1206$

[36] Chou C, Condron L, Belland JC. A review of the Research on Internet Addiction. Educational Psychology Review. 2005; 17: 363-388. http://dx.doi.org/10.1007/s10648-005-8138-1
[37] Nalwa K, Anand AP. Internet Addiction in Students: A cause of Concern. Cyber Psychology \& Behavior. 2003; 6: 653-656. PMID:14756932. http://dx.doi.org/10.1089/10949310332 2725441

[38] Beranuy M, Oberst U, Carbonell X, et al. Problematic Internet and Mobile Phone use and Clinical Symptoms in College Students: The role of Emotional Intelligence. Computers in Human Behavior. 2009; 25: 1182-1187.http://dx.doi.org/10.1016/j.chb.2009.03 .001

[39] Li D, Zhang W, Li X, et al. Stressful Life Events and Problematic Internet Use by Adolescent Females and Males: A mediated Moderation Model. Computers in Human Behavior. 2010; 26: 1199-1207. http://dx.doi.org/10.1016/j.chb.2010.03.031

[40] Holtz P, Appel M. Internet Use and Video Gaming Predict Problem Behavior in Early Adolescence. Journal of Adolescence. 2011; 34: 49-58. PMID:20303580. http://dx.doi.org/10.1016/j . a dolescence. 2010.02.004

[41] Pence P. Emotional Intelligence, Motivation, and Retention among Undergraduate Students Attending Associate-degree Nursing Programs in Illinois. Published Doctoral Dissertation, School of Advanced Studies, University of Phoenix. 2010.

[42] Mahmoud H, Abd El-Dayem S, Mousa M. Emotional Intelligence among Baccalaureate Students at the Faculty of Nursing, Alexandria University, Egypt: A Cross-sectional Study. Journal of Education and Practice. 2013; 4(27): 49-62. 